\title{
Introducing Near-Death Research Findings into Psychotherapy
}

\author{
John M. McDonagh, Ph.D., A.B.P.P. \\ Cold Spring Harbor, NY
}

ABSTRACT: Traditionally, it has been regarded as inappropriate for a therapist to introduce issues of spirituality or religion into a psychotherapy session. I departed from this convention and discussed the rationale and results of doing so with adult and adolescent suicidal patients originally in 1979, and have been doing so ever since. Engelbert Winkler (2003) recently discussed his experience in using information about near-death experiences (NDEs) with a suicidal child. This paper discusses the rationale for introducing such material in cases of bereavement as well. I discuss introducing the client to empirical findings in the NDE area as "psycheducational."

KEY WORDS: bereavement; near-death experience; psychotherapy; psychoeducation; suicide.

The dominant policy in the field of psychotherapy regarding spiritual and religious beliefs is that the therapist must remain scrupulously neutral when such topics are presented by the client. No doubt this may have its origins in the theoretical underpinnings of psychoanalysis, which required that the analyst remain as an unknown quantity so that the analysand could project his or her psychological material onto a blank screen without any contamination by the analyst's psychological make-up. The requirement to avoid offering any opinions on spiritual or religious matters was probably further strengthened by the fact that many of the early psychoanalysts were either nonreligious or antithetical to religion or spirituality. Therefore, it was a sharp break from my training when I decided to introduce certain findings of Raymond Moody $(1975,1977)$ on the

John McDonagh, Ph.D., is a licensed clinical psychologist in private practice in Cold Spring Harbor, NY. Reprint requests should be addressed to Dr. McDonagh at 2 Carnegie Avenue, Cold Spring Harbor, NY 11724; e-mail: j.mc.donagh@worldnet.att.net. 
near-death experiences (NDEs) of suicidal patients into the therapy of one of my suicidal clients.

What had impressed me in Moody's account of his interviews with suicidal NDE survivors is that none of them ever attempted suicide again. Furthermore, several of the nonsuicidal survivors corroborated the lessons from the suicidal survivors that in the NDE state they "learned" that suicide was not desirable and that it could lead to a perpetuation of the dilemma that prompted them to kill themselves (Moody, 1977).

At the time that I discovered Moody's writings (1977), I was seeing a teenaged girl in therapy who was suffering from chronic major depression. This young woman was also being seen by a psychiatrist and had tried several antidepressant medications with no significant lifting of her symptoms. I had been working with her for about a year, with no sustained improvement. She would exhibit short-term improvement, but as soon as another crisis surfaced in her life, her depressed mood deepened and she returned to a preoccupation with suicide. In reading Moody's accounts, I was also impressed by the fact that he devoted some of his discussion to examining the independent verification of the content of what the NDE survivors reported. So, it seemed to me that this was not just another wild claim that one might see in a grocery store tabloid, but a reasoned and sober account by a respected psychiatrist. Even though Moody disavowed that his accounts "proved" the existence of an afterlife, I reasoned that he at least had presented some evidence that was suggestive of a degree of personal survival of bodily death. To someone such as myself, raised in the Catholic faith, but at that time disbelieving in the afterlife, these accounts seemed very significant.

Many of us may have searched for "truth" in various philosophies and religions, and have been confused by the great plethora of philosophical systems and religions that abound. Out of all of these varied systems, the pragmatism of William James (1907) seemed to offer to me some framework from which to evaluate Moody's findings. Moody said that after experiencing the NDE, no suicidal patient in his acquaintance ever attempted suicide again. James had pointed out that if actions taken in accord with certain beliefs resulted in observable changes that were in accord with these beliefs, then this demonstrated that such beliefs had some truth value. It could then be said that the beliefs "worked."

What I took from this was that whatever the NDE survivors learned during the NDE "worked" insofar as their behavior changed perma- 
nently: they did not attempt suicide again. That is what I wanted for my client: to learn that suicide was not an option. Would this belief "work" for my client the way it worked for Moody's NDE survivors? The difference between Moody's patients and my client is that the former had NDEs. However, I reasoned, if my client were exposed to the accounts given by Moody's patients, she could learn vicariously. The input would change her belief system in a way that traditional cognitive therapy had not been able to do. With the foregoing as my rationale, I decided to introduce my client to Moody's findings.

Because my client's ability to focus her attention was impaired, I doubted that she would read Moody's books if I lent them to her, so I decided to read selected passages to her. What occurred was quite dramatic. She cried profusely when she heard the report of the NDE survivor that the dilemma that plagued her in this life would continue into the next plane of existence. However, after this very tearful session, my client began to dig much deeper into herself to come to grips with the dilemmas that were causing her such distress. In the weeks that followed, there was more psychological movement than there had been in many months. It was as if the desperation option of suicide no longer existed for her, so she would have to focus more energy on her remaining options. I cannot say that this intervention resulted in the total remission of her depression, but I can say that she was no longer suicidal (McDonagh, 1979).

Encouraged by the positive effect of introducing NDE-related material on suicide, I did the same with another client and witnessed virtually the same result. Even though this second client was not planning suicide, he frequently fantasized about dying and sometimes pictured himself committing suicide. After the introduction of the above material, these fantasies stopped. My use of NDE material in psychotherapy sessions has evolved to the point that when clients begin to express suicidal ideation, I ask them what they think happens after death. Not surprisingly, there is a variety of responses.

Many say that after death, they cease to exist and there is nothing. A large percentage say they do not know what happens and have never given it much thought. I then discuss with them that there are a number of NDE survivors who have come back with very interesting reports, and that it might benefit them to listen to what they have to say. In more recent years since these first interventions, I have used a videotape narrated by Moody (1992) in which he interviewed several NDE survivors. Over the 25 years since I began using NDE material, about 20 cases have involved suicidal clients, some with previous 
suicidal attempts. In all of that time, the suicidal ideation of all of these clients has diminished or disappeared, and none to my knowledge ever attempted suicide. A few of them have contacted me years later and have said things such as, "That tape saved my life."

Another group of clients that I have found to benefit from watching Moody's videotape are the bereaved. My observation has been that those clients who already believe in some kind of afterlife are better able to deal with the death of a loved one than those who have no such belief. The reason seems obvious: those who believe in an afterlife have hope that they will one day be reunited with their loved one, while for those who have no such belief, the separation by death is final. After watching the Moody videotape, my clients begin to question their assumptions about death. The statements by NDE survivors in the tape, on the importance of behaving in a loving way in this life, also sometimes begin a process of reevaluation by the client of his or her own priorities. Some clients who were not able to visit their loved ones before they died have derived solace from realizing that the recently deceased person may well have been aware of their efforts to visit, and of the love which the client was not able to express. In summary, the material in the videotaped interviews often gives comfort to the grieving client, but it also generates movement on personal issues that go beyond the grieving process.

Sometimes the introduction of the NDE material results in a reaction of skepticism. I usually reply that many people are skeptical of the validity of the data, but that I want the clients to be informed about the research, and if they feel so inclined, to continue reading on their own. One resource I refer them to is Kevin Williams' website (http:// www.near-death.com/) which discusses the case of Pam Reynolds, first described by Michael Sabom (1998). Reynolds had undergone brain surgery to remove an aneurysm. Because of the size and location of the aneurysm, her body temperature had to be lowered to 60 degrees; blood was drained from her head; her heartbeat and breathing stopped; and her brainwaves were flattened. She remained in this clinically dead state for about an hour while the surgery was performed. She emerged from her clinical death reporting many detailed observations of occurrences coincident with the surgery that were independently verified (Sabom, 1998).

I see this dialogue with my clients as similar to educating them with results of empirical research in any other field that is pertinent to their clinical concerns, such as child-rearing issues or side-effects of psychotropic drugs. It falls clearly under the rubric of "psychoeducation." As 
with other categories of psychoeducation, I would be failing in my professional responsibility if I deprived them of such important information that my experience causes me to believe would be helpful to them. The fact that this particular type of "psychoeducation" involves empirical data that might lead one to explore the "spiritual realm" should not disqualify it as legitimate psychoeducational material.

In summary, the research that has so painstakingly explored and documented the NDE over the years, and my reading of and listening personally to the accounts of experiencers, have opened my eyes to a valuable psychotherapeutic tool. This whole field of inquiry has enriched me many times over as I have been able to share it with my clients whose lives have also been enriched and, in many cases, lengthened.

\section{References}

James, W. (1907). Pragmatism: A New Name for Some Old Ways of Thinking. New York, NY: Longman Green.

McDonagh, J. (1979, September). Bibliotherapy with suicidal patients. Paper presented at the $87^{\text {th }}$ Annual Convention of the American Psychological Association, New York, NY.

Moody, R. (1975). Life after life. Covington, GA: Mockingbird Books.

Moody, R. (1977). Reflections on life after life. St. Simon's Island, GA: Mockingbird Books.

Moody, R. (1992). Life after life [Videotape]. Nashville, TN: Cascom. (Distributed by ShelfMasters, PO Box 5673, Lafayette, IN 47903; www.ShelfMasters.com)

Sabom, M. (1998). Light and death: One doctor's fascinating account of near-death experiences. Grand Rapids. MI: Zondervan.

Winkler, E. (2003). The Elias Project: Using near-death experience potential in therapy. Journal of Near-Death Studies, 22, 79-82. 